\title{
A Simple Iterative Approach to Shape and Depth Estimation from SP Residual Anomalies
}

\author{
E.M. Abdelrahman, T.M. El-Araby and K.S. Essa \\ Geophysics Department, Faculty of Science, \\ Cairo University, Giza, Egypt
}

Received: 5/1/2002 Revised: 17/4/2002 Accepted: 8/4/2003

\begin{abstract}
Aвstract. We have developed a simple numerical approach to define shape and depth from residual SP anomalies caused by simple geologic structures. By defining the anomaly value at the origin $\mathrm{V}(0)$ and the anomaly values at two equidistant points from the origin on the profile $(\mathrm{V}(\mathrm{N})$ and $\mathrm{V}(-\mathrm{N}))$, the problem of depth determination from residual SP anomalies has been transformed into finding a solution to a nonlinear equation for each shape factor. The computed depths are plotted against the shape factors on a graph. All points for each two equidistant points from the origin are connected by a continuous curve (depth curve). The solution for the shape and depth of the buried structure is read at the common intersection of the depth curves. The method is applied to theoretical data without and with (10\%) random noise and tested on a field example from Colorado.
\end{abstract}

\section{Introduction}

SP data are usually used to explore rocks and minerals, especially metallic sulfides and graphite, which reveal themselves as SP anomalies hidden in the regional field and/or masked by the topographic effects. However, sometimes an individual SP anomaly is found that stands out so clearly that it can be separated from the regional background and the topographic interfaces, and is so simple in appearance that it can be modeled as a simple polarized body. In this case, quantitative methods of interpretation can be used to determine the shape and depth of the polarized body. The methods include least-squares methods (Abdelrahman et al., 1997a), gradient analysis method (Abdelrahman et al., 1997b) 
second derivative analysis method (Abdelrahman et al., 1998), and moving average residual analysis method (Abdelrahman et al., 1999).

In this paper, a simple iterative method is presented to estimate the shape and depth of a buried structure from residual SP anomalies. The method involves using a relationship between the shape and the depth to the source and a combination of symmetrical observations around the origin of the profile. The method is applied to synthetic data without and with (10\%) random noise and tested on a field example from Colorado.

\section{The Method}

Following Battacharya and Roy (1981), the general expression for SP anomaly of an arbitrary polarized structure is given by

$$
V\left(x_{i}, z, \theta, q\right)=K \frac{x_{i} \cos \theta+z \sin \theta}{\left(x_{i}^{2}+z^{2}\right)^{q}}, i=1,2,3, \ldots N,
$$

where $\mathrm{z}$ is the depth, $\theta$ is the polarization angle, $\mathrm{K}$ is the electrical dipole moment or the magnitude of polarization, $\mathrm{x}$ is a horizontal position coordinate, and $\mathrm{q}$ is the shape factor related roughly to shape of the buried structure. For example, the shape factor (q) for a sphere is 1.5 , for a horizontal cylinder is 1.0, and for a semi-infinite vertical cylinder is 0.5 .

At the origin $\left(x_{i}=0\right)$, equation (1) gives the following relationship:

$$
\begin{aligned}
K & =\frac{V(0) Z^{2 q-1}}{\sin \theta}, \\
\frac{V(N)}{V(0)} & =Z^{2 q-1}\left[\frac{N \cot \theta+z}{\left(N^{2}+Z^{2}\right)^{q}}\right],
\end{aligned}
$$

Using equation (1), we obtain the following normalized equation at $\mathrm{x}_{\mathrm{i}}= \pm \mathrm{N}$, $\mathrm{N}=1,2,3$

$$
\frac{\mathrm{V}(\mathrm{N})}{\mathrm{V}(0)}=\mathrm{Z}^{2 \mathrm{q}-1}\left[\frac{-\mathrm{N} \cot \theta+\mathrm{z}}{\left(\mathrm{N}^{2}+\mathrm{z}^{2}\right)^{\mathrm{q}}}\right], \begin{aligned}
& \mathrm{X}_{\mathrm{i}}=\mathrm{N} \\
& \mathrm{X}_{\mathrm{i}}=-\mathrm{N}
\end{aligned}
$$

Let $\mathrm{F}=(\mathrm{V}(\mathrm{N})-\mathrm{V}(-\mathrm{N})) / \mathrm{V}(0)$, then from equations (3) and (4) we obtain

$$
\theta=\tan ^{-1}\left\{\frac{2 \mathrm{Nz}^{2 \mathrm{q}-1}}{2 \mathrm{~F}\left(\mathrm{~N}^{2}+\mathrm{z}^{2}\right)^{\mathrm{q}}}\right\} .
$$


Also, let $\mathrm{T}=(\mathrm{V}(\mathrm{N})+\mathrm{V}(-\mathrm{N})) / \mathrm{V}(0)$, then from equations (3) and (4) we obtain

$$
\mathrm{z}=\left[\frac{\mathrm{T}\left(\mathrm{N}^{2}+\mathrm{z}^{2}\right)^{\mathrm{q}}}{2}\right]^{1 / 2 q} \text {. }
$$

Equation (6) can be solved using a simple iterative method (Demidovich and Maron, 1972). The iterative form of equation (6) is given by

$$
\mathrm{z}_{\mathrm{f}}=\mathrm{f}\left(\mathrm{z}_{\mathrm{j}}\right)
$$

where $z_{j}$ is the initial depth and $z_{f}$ is the revised depth. We will use $z_{f}$ as $z_{j}$ for next iteration. The iteration stops when $|z f-z j|<e$, where e is a small predetermined real number close to zero.

The source depth is determined by solving one nonlinear equation in z. Any initial guess for $\mathrm{z}$ works well because there is only one global minimum.

Once $\mathrm{z}$ is known, the polarization angle, $\theta$, can be determined from equation (5). Knowing $\mathrm{z}$ and $\theta$, the electrical dipole moment, $\mathrm{K}$, can be determined from equation (2).

To this stage, we have assumed knowledge of the axes of the SP profile, so that $\mathrm{V}(0)$ can be determined. Otherwise, $\mathrm{V}(0)$ can be determined using the method described by Stanley (1977). As illustrated in Figure 1, the line M-m intersects the anomaly profile at $x_{i}=0$. However, the accuracy of the result obtained using equation (6) depends upon the accuracy to which the shape factor (q) can be assumed or determined from other geologic and/or geophysical data.

\section{Solution Using the Depth Curves Method}

Equation (6) can be used not only to determine the depth but also to simultaneously estimate the shape of the buried structure (shape factor). The procedure is as follows:

1 - Determine the origin of the observed SP anomaly curve $\left(x_{i}=0\right)$ using Stanley's method (1977).

2 - Digitize the anomaly profile at several points including the central point $\left(\mathrm{x}_{\mathrm{i}}=0\right)$.

3 - For a fixed $\mathrm{N}$ value, determine the depth of the buried structure using equation (6) for each shape factor (q). The depth obtained is plotted against the shape factor representing a continuous depth curve. The depth curves should intersect at the true answer because equation (6) has only two unknowns ( $\mathrm{z}, \mathrm{q})$ to be determined.

The present approach is more advantageous than a full least-squares inversion technique in determining the model parameters of a buried structure from residual SP anomalies. The experience with the minimization technique for two or more unknowns is that it always produces good results from syn- 
thetic data with or without random noise. In the case of field data, good results may only be obtained when using very good initial guess on the model parameters $(\mathrm{K}, \mathrm{z}, \mathrm{q}, \theta)$. The optimization problem for the shape, depth, polarization angle, and electrical dipole moment is highly nonlinear, increasing the number of parameters to be solved simultaneously increases the dimensionality of the energy surface, thereby generally increasing the probability of the optimization stalling in a local minimum. This is why we propose the above method rather than using a full least-squares minimization method in determining the shape and depth of a buried structure from observed SP anomalies.

\section{Synthetic Examples}

Figures 2, 3, and 4 show three different SP anomalies due to a semi-infinite vertical cylinder $(\mathrm{z}=1 \mathrm{~m}, \mathrm{q}=0.5)$, a horizontal cylinder $(\mathbf{z}=\mathbf{3} \mathrm{m}, \mathrm{q}=1.0)$, and a sphere $(\mathrm{z}=5 \mathrm{~m}, \mathrm{q}=1.5)$, respectively. Other model parameters are inserted in Figures 2,3, and 4. Equation (6) was applied to each of the three residual anomaly profiles, yielding depth solutions for all possible (q) values where $\mathrm{N}=1,3$, 5 , and $7 \mathrm{~m}$, (Tables 1, 2, and 3). The computed depths are plotted against the shape factors representing continuous depth curves for the different $\mathrm{N}$ values. The results are summarized in Figures 5, 6, and 7, respectively.

The correct solution for $\mathrm{q}=0.5$ theoretical model occurs at the common intersection of the depth curves. Figure 5 shows the intersection at the correct location of $\mathrm{z}=1 \mathrm{~m}$ and $\mathrm{q}=0.5$. Figure 6 shows that the depth curves intersect at the correct point $\mathrm{z}=3 \mathrm{~m}$ and $\mathrm{q}=1.0$. On the other hand, Figure 7 shows the intersection at the correct location of $\mathrm{z}=5 \mathrm{~m}$ and $\mathrm{q}=1.5$. In all cases, the solution for shape factor and depth are in excellent agreement with the parameters given in Figures 2, 3, and 4.

Moreover, random errors of $10 \%$ were added to each SP anomaly to produce three different noisy anomalies. Adapting the same interpretation procedure used in above examples, the results are given in Tables 4, 5, and 6 and shown in Figures 8, 9, and 10, respectively.

When the data contain noise, the depth curves intersect each other in a very narrow region. The central point of the intersection region (intersection points) occur at the approximate locations $\mathrm{q}=0.49$ and $\mathrm{z}=0.94 \mathrm{~m}, \mathrm{q}=1.04$ and $\mathrm{z}=$ $3.30 \mathrm{~m}$, and $\mathrm{q}=1.45$ and $\mathrm{z}=5.05 \mathrm{~m}$ for the first, second and third models, respectively. In all cases, the solution for depth and shape are in very good agreement with the parameters given in Figures 2, 3, and 4. This demonstrates that our method will give reliable results even when the SP residual anomaly contains measurement errors and/or geologic noise within (10\%) magnitude of the SP anomaly. 
TABLE 1. Theoretical example in a case where the model parameters are $\mathrm{z}=1 \mathrm{~m}, \mathrm{q}=0.5, \theta=70^{\circ}$, $\mathrm{K}=-100 \mathrm{mV}$, profile length $=40 \mathrm{~m}$, and sampling interval $=1 \mathrm{~m}$.

\begin{tabular}{|c|c|c|c|c|}
\hline \multirow{2}{*}{$\begin{array}{l}\text { Shape factor } \\
\text { (q) }\end{array}$} & \multicolumn{4}{|c|}{ Computed depths } \\
\hline & $\mathrm{N}=1 \mathrm{~m}$ & $\mathrm{~N}=3 \mathrm{~m}$ & $\mathrm{~N}=5 \mathrm{~m}$ & $\mathrm{~N}=7 \mathrm{~m}$ \\
\hline 0.2 & 0.463397 & 0.168970 & 0.085176 & 0.052650 \\
\hline 0.3 & 0.678094 & 0.445161 & 0.331726 & 0.268912 \\
\hline 0.4 & 0.851746 & 0.732300 & 0.658176 & 0.609370 \\
\hline 0.5 & 1.000000 & 1.000000 & 1.000000 & 1.000000 \\
\hline 0.6 & 1.130975 & 1.244297 & 1.331284 & 1.398601 \\
\hline 0.7 & 1.249346 & 1.467440 & 1.644050 & 1.786598 \\
\hline 0.8 & 1.358050 & 1.672623 & 1.937128 & 2.157094 \\
\hline 0.9 & 1.459062 & 1.862738 & 2.211702 & 2.508391 \\
\hline 1.0 & 1.553774 & 2.040166 & 2.469620 & 2.840963 \\
\hline 1.1 & 1.643210 & 2.206816 & 2.712775 & 3.156118 \\
\hline 1.2 & 1.728150 & 2.364216 & 2.942898 & 3.445401 \\
\hline 1.3 & 1.809198 & 2.513598 & 3.161501 & 3.740343 \\
\hline 1.4 & 1.886837 & 2.655964 & 3.369884 & 4.012359 \\
\hline 1.5 & 1.961459 & 2.792136 & 3.569157 & 4.272719 \\
\hline
\end{tabular}


TABLE 2. Theoretical example in a case where the model parameters are $\mathrm{z}=3 \mathrm{~m}, \mathrm{q}=1.0, \theta=50^{\circ}$, $\mathrm{K}=-1000 \mathrm{mV}$, profile length $=40 \mathrm{~m}$, and sampling interval $=1 \mathrm{~m}$.

\begin{tabular}{|c|c|c|c|c|}
\hline \multirow{2}{*}{$\begin{array}{l}\text { Shape factor } \\
\text { (q) }\end{array}$} & \multicolumn{4}{|c|}{ Computed depths } \\
\hline & $\mathrm{N}=1 \mathrm{~m}$ & $\mathrm{~N}=3 \mathrm{~m}$ & $\mathrm{~N}=5 \mathrm{~m}$ & $\mathrm{~N}=7 \mathrm{~m}$ \\
\hline 0.3 & 1.541615 & 0.995620 & 0.548922 & 0.313973 \\
\hline 0.4 & 1.821651 & 1.390193 & 0.966935 & 0.684992 \\
\hline 0.5 & 2.064741 & 1.732051 & 1.372487 & 1.099525 \\
\hline 0.6 & 2.282402 & 2.034283 & 1.749976 & 1.516113 \\
\hline 0.7 & 2.481207 & 2.306464 & 2.098388 & 1.917902 \\
\hline 0.8 & 2.665322 & 2.555238 & 2.420581 & 2.299362 \\
\hline 0.9 & 2.837577 & 2.785287 & 2.720049 & 2.659705 \\
\hline 1.0 & 3.000000 & 3.000000 & 3.000000 & 3.000000 \\
\hline 1.1 & 3.154094 & 3.201903 & 3.263164 & 3.321939 \\
\hline 1.2 & 3.301024 & 3.392924 & 3.511800 & 3.627321 \\
\hline 1.3 & 3.000000 & 3.574569 & 3.747772 & 3.917848 \\
\hline 1.4 & 3.576863 & 3.748037 & 3.972618 & 4.195052 \\
\hline 1.5 & 3.707110 & 3.914298 & 4.187616 & 4.460286 \\
\hline
\end{tabular}


TABLE 3. Theoretical example in a case where the model parameters are $\mathrm{z}=5 \mathrm{~m}, \mathrm{q}=1.5, \theta=30^{\circ}$, $\mathrm{K}=-10000 \mathrm{mV}$, profile length $=40 \mathrm{~m}$, and sampling interval $=1 \mathrm{~m}$.

\begin{tabular}{|c|c|c|c|c|}
\hline \multirow{2}{*}{$\begin{array}{l}\text { Shape factor } \\
\text { (q) }\end{array}$} & \multicolumn{4}{|c|}{ Computed depths } \\
\hline & $\mathrm{N}=1 \mathrm{~m}$ & $\mathrm{~N}=3 \mathrm{~m}$ & $\mathrm{~N}=5 \mathrm{~m}$ & $\mathrm{~N}=7 \mathrm{~m}$ \\
\hline 0.3 & 1.148412 & 1.569715 & 0.898027 & 0.465400 \\
\hline 0.4 & 2.512244 & 2.037520 & 1.416803 & 0.922929 \\
\hline 0.5 & 2.829964 & 2.436966 & 1.889822 & 1.401842 \\
\hline 0.6 & 3.115580 & 2.789056 & 2.316988 & 1.865902 \\
\hline 0.7 & 3.377196 & 3.106420 & 2.705131 & 2.303975 \\
\hline 0.8 & 3.619993 & 3.397139 & 3.061088 & 2.714446 \\
\hline 0.9 & 3.847524 & 3.666678 & 3.390472 & 3.098985 \\
\hline 1.0 & 4.062349 & 3.918910 & 3.697696 & 3.460188 \\
\hline 1.1 & 4.266383 & 4.156685 & 3.986210 & 3.800711 \\
\hline 1.2 & 4.461101 & 4.382163 & 4.258730 & 4.122981 \\
\hline 1.3 & 4.647676 & 4.597026 & 4.517424 & 4.429116 \\
\hline 1.4 & 4.827038 & 4.802609 & 4.764038 & 4.720938 \\
\hline 1.5 & 5.000000 & 5.000000 & 5.000000 & 5.000000 \\
\hline
\end{tabular}




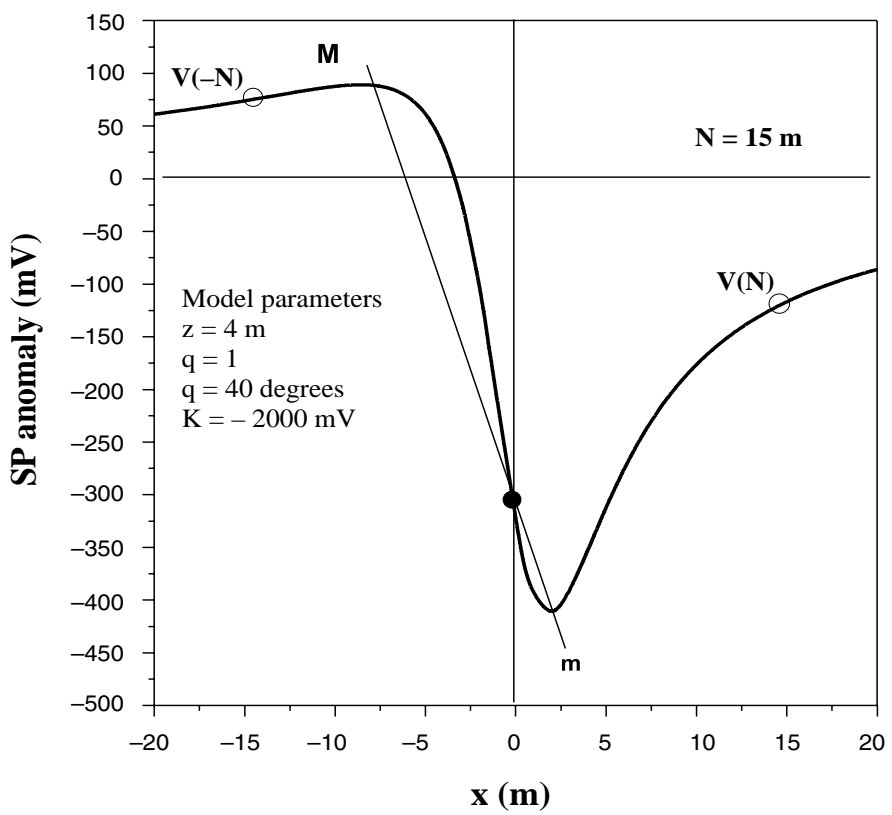

Fig. 1. A typical self-potential anomaly profile over a horizontal cylinder. Identified on this profile are the maximum value $(\mathrm{M})$ and the minimum value $(\mathrm{m})$ from which the origin of the profile can be determined using Stanley's method (1977).

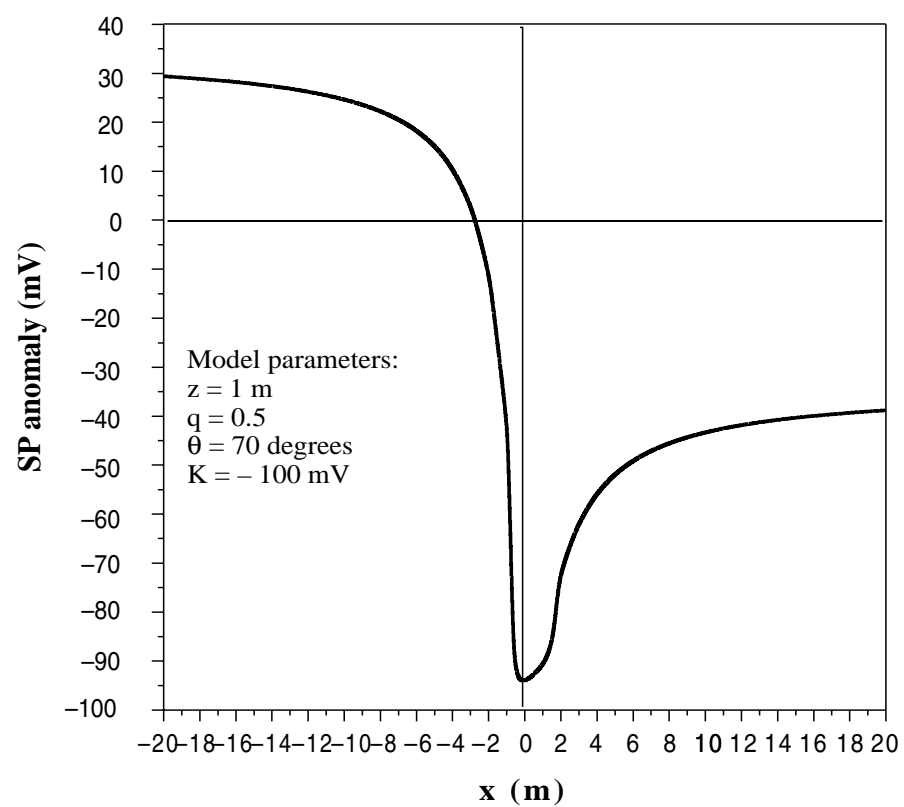

Fig. 2. A self-potential anomaly over a semi-infinite vertical cylinder. The model parameters are: $\mathrm{z}=1 \mathrm{~m}, \mathrm{q}=0.5, \mathrm{~K}=-100 \mathrm{mV}$, and $\theta=70$ degrees. 


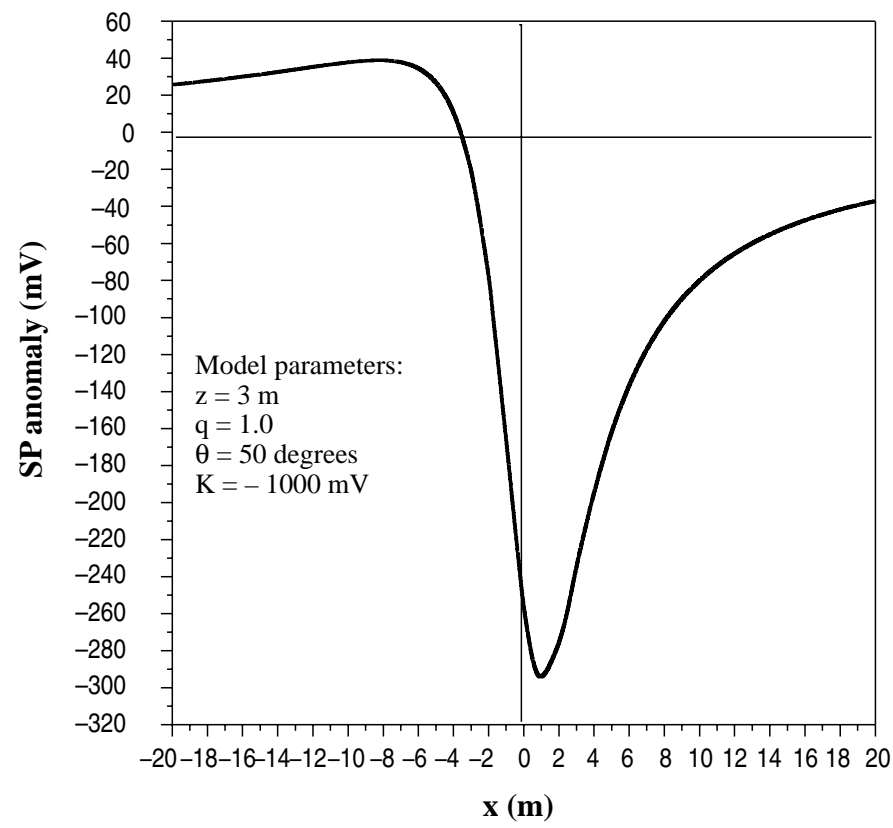

Fig. 3. A self-potential anomaly over a horizontal cylinder. The model parameters are: $\mathrm{z}=3 \mathrm{~m}$, $\mathrm{q}=1.0, \mathrm{~K}=-1000 \mathrm{mV}$, and $\theta=50$ degrees.

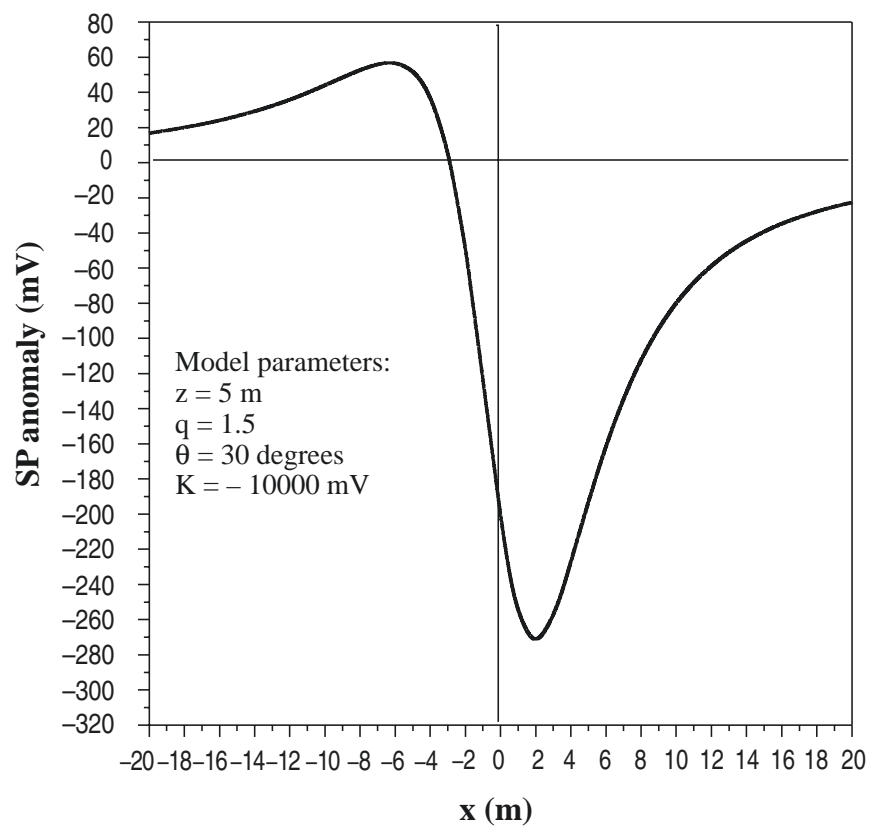

FIG. 4. A self-potential anomaly over a sphere. The model parameters are: $\mathrm{z}=5 \mathrm{~m}, \mathrm{q}=1.5$, $\mathrm{K}=-10000 \mathrm{mV}$, and $\theta=30$ degrees. 
TABLE 4. Theoretical example with $10 \%$ random noise in a case where the model parameters are $\mathrm{z}=1 \mathrm{~m}, \mathrm{q}=0.5, \theta=70^{\circ}, \mathrm{K}=-100 \mathrm{mV}$, profile length $=40 \mathrm{~m}$, and sampling interval $=1 \mathrm{~m}$.

\begin{tabular}{|c|c|c|c|c|}
\hline \multirow{2}{*}{$\begin{array}{l}\text { Shape factor } \\
\text { (q) }\end{array}$} & \multicolumn{4}{|c|}{ Computed depths } \\
\hline & $\mathrm{N}=1 \mathrm{~m}$ & $\mathrm{~N}=3 \mathrm{~m}$ & $\mathrm{~N}=5 \mathrm{~m}$ & $\mathrm{~N}=7 \mathrm{~m}$ \\
\hline 0.3 & 0.634272 & 0.462250 & 0.300514 & 0.298033 \\
\hline 0.4 & 0.802950 & 0.754085 & 0.610616 & 0.658554 \\
\hline 0.5 & 0.946895 & 1.024918 & 0.940563 & 1.064954 \\
\hline 0.6 & 1.073964 & 1.271531 & 1.263166 & 1.475448 \\
\hline 0.7 & 1.188714 & 1.496537 & 1.569296 & 1.872570 \\
\hline 0.8 & 1.294019 & 1.703313 & 1.857044 & 2.250318 \\
\hline 0.9 & 1.391813 & 1.894846 & 2.127143 & 2.607593 \\
\hline 1.0 & 1.483459 & 2.073572 & 2.381168 & 2.945264 \\
\hline 1.1 & 1.569963 & 2.241431 & 2.620840 & 3.264894 \\
\hline 1.2 & 1.652084 & 2.399973 & 2.847780 & 3.568195 \\
\hline 1.3 & 1.730416 & 2.550444 & 3.063427 & 3.856813 \\
\hline 1.4 & 1.805431 & 2.693854 & 3.269031 & 4.132242 \\
\hline 1.5 & 1.877512 & 2.831032 & 3.465666 & 4.395806 \\
\hline
\end{tabular}


TABLE 5. Theoretical example with $10 \%$ random noise in a case where the model parameters are $\mathrm{z}=3 \mathrm{~m}, \mathrm{q}=1.0, \theta=50^{\circ}, \mathrm{K}=-1000 \mathrm{mV}$, profile length $=40 \mathrm{~m}$, and sampling interval $=1 \mathrm{~m}$.

\begin{tabular}{|c|c|c|c|c|}
\hline \multirow{2}{*}{$\begin{array}{l}\text { Shape factor } \\
\text { (q) }\end{array}$} & \multicolumn{4}{|c|}{ Computed depths } \\
\hline & $\mathrm{N}=1 \mathrm{~m}$ & $\mathrm{~N}=3 \mathrm{~m}$ & $\mathrm{~N}=5 \mathrm{~m}$ & $\mathrm{~N}=7 \mathrm{~m}$ \\
\hline 0.3 & 1.602298 & 1.039461 & 0.561403 & 0.324448 \\
\hline 0.4 & 1.890466 & 1.440337 & 0.983799 & 0.702196 \\
\hline 0.5 & 2.140816 & 1.786877 & 1.392315 & 1.121900 \\
\hline 0.6 & 2.365098 & 2.093023 & 1.771955 & 1.542349 \\
\hline 0.7 & 2.570031 & 2.368681 & 2.122050 & 1.947094 \\
\hline 0.8 & 2.759877 & 2.620648 & 2.445642 & 2.330905 \\
\hline 0.9 & 2.937534 & 2.853683 & 2.746327 & 2.693195 \\
\hline 1.0 & 3.105079 & 3.071223 & 3.027373 & 3.035158 \\
\hline 1.1 & 3.264062 & 3.275823 & 3.291542 & 3.358568 \\
\hline 1.2 & 3.415670 & 3.469432 & 3.541118 & 3.665277 \\
\hline 1.3 & 3.560844 & 3.653570 & 3.777978 & 3.957022 \\
\hline 1.4 & 3.700336 & 3.829448 & 4.003671 & 4.235361 \\
\hline 1.5 & 3.834765 & 3.998045 & 4.219482 & 4.501665 \\
\hline
\end{tabular}


TABLE 6. Theoretical example with $10 \%$ random noise in a case where the model parameters are $\mathrm{z}=5 \mathrm{~m}, \mathrm{q}=1.5, \theta=30^{\circ}, \mathrm{K}=-10000 \mathrm{mV}$, profile length $=40 \mathrm{~m}$, and sampling interval $=1 \mathrm{~m}$.

\begin{tabular}{|c|c|c|c|c|}
\hline \multirow{2}{*}{$\begin{array}{l}\text { Shape factor } \\
\text { (q) }\end{array}$} & \multicolumn{4}{|c|}{ Computed depths } \\
\hline & $\mathrm{N}=1 \mathrm{~m}$ & $\mathrm{~N}=3 \mathrm{~m}$ & $\mathrm{~N}=5 \mathrm{~m}$ & $\mathrm{~N}=7 \mathrm{~m}$ \\
\hline 0.3 & 2.240782 & 1.651224 & 1.095464 & 0.535094 \\
\hline 0.4 & 2.617755 & 2.128494 & 1.601396 & 1.026281 \\
\hline 0.5 & 2.94715 & 2.535846 & 2.065825 & 1.529190 \\
\hline 0.6 & 3.243379 & 2.894995 & 2.486546 & 2.010699 \\
\hline 0.7 & 3.514788 & 3.218861 & 2.869420 & 2.462137 \\
\hline 0.8 & 3.766729 & 3.515665 & 3.220809 & 2.883404 \\
\hline 0.9 & 4.002868 & 3.790959 & 3.546084 & 3.277066 \\
\hline 1.0 & 4.225845 & 4.048672 & 3.849518 & 3.646258 \\
\hline 1.1 & 4.437644 & 4.291691 & 4.134478 & 3.993969 \\
\hline 1.2 & 4.639791 & 4.522210 & 4.40363 & 4.32284 \\
\hline 1.3 & 4.833487 & 4.741933 & 4.659104 & 4.635132 \\
\hline 1.4 & 5.019725 & 4.952215 & 4.902623 & 4.932761 \\
\hline 1.5 & 5.199301 & 5.154156 & 5.13598 & 5.217350 \\
\hline
\end{tabular}




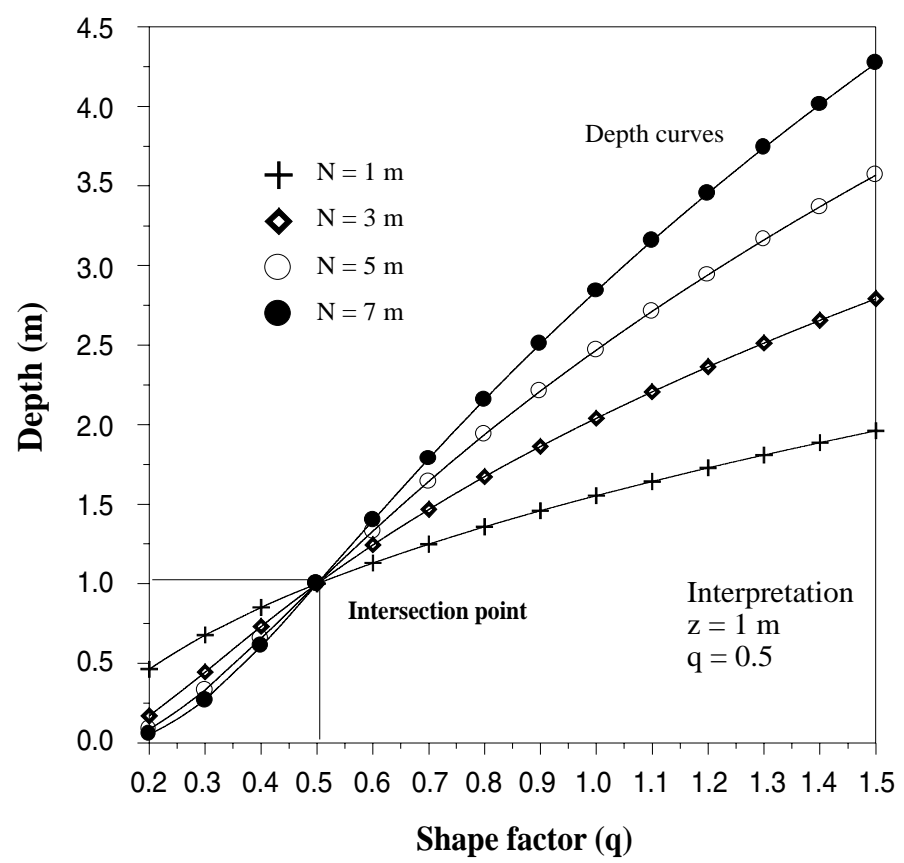

FIG. 5. Data interpretation of Figure 2 using the present depth cuves method.

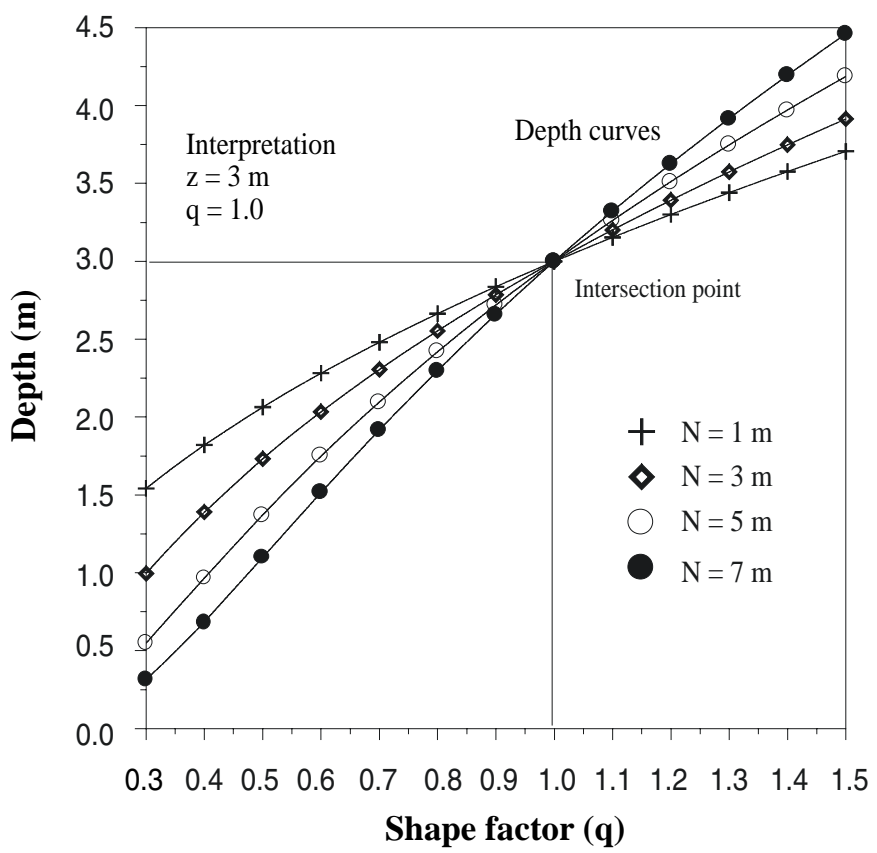

FIG. 6. Data interpretation of Figure 3 using the present depth curves method. 


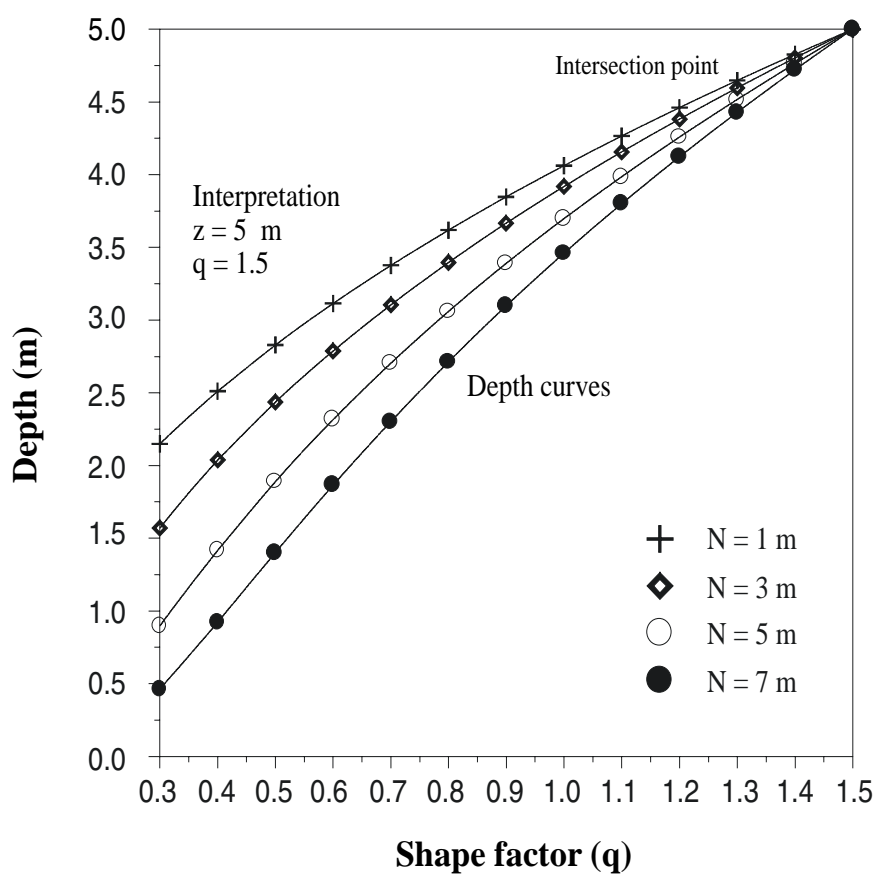

FIG. 7. Data interpretation of Figure 4 using the present depth curves method.

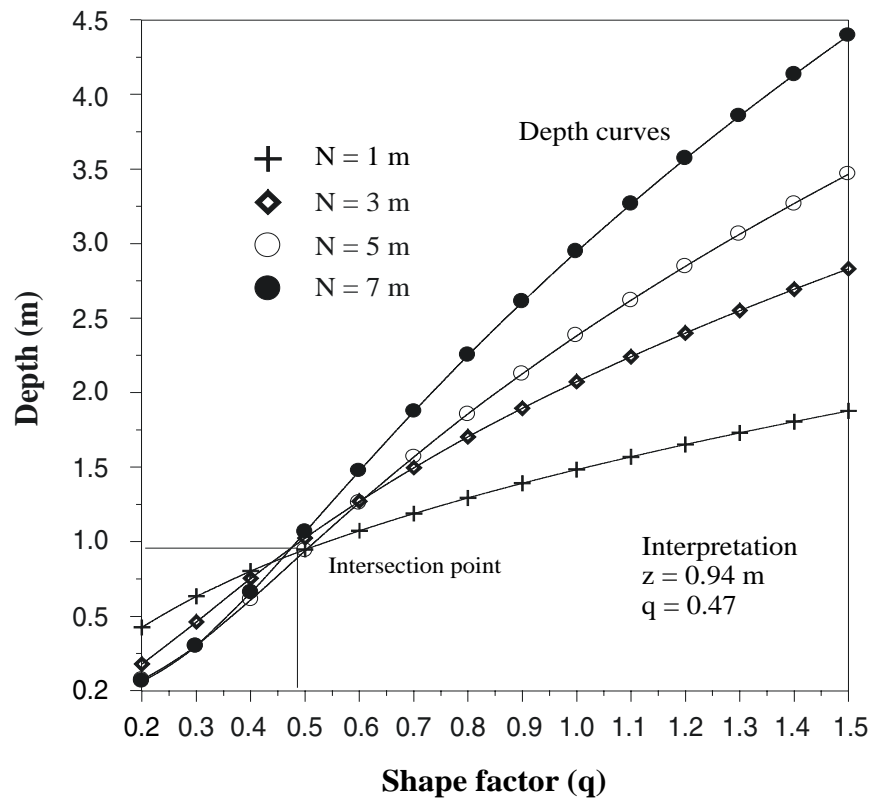

FIG. 8. Data interpretation of Figure 2 after adding $10 \%$ random errors using the present depth curves method. 


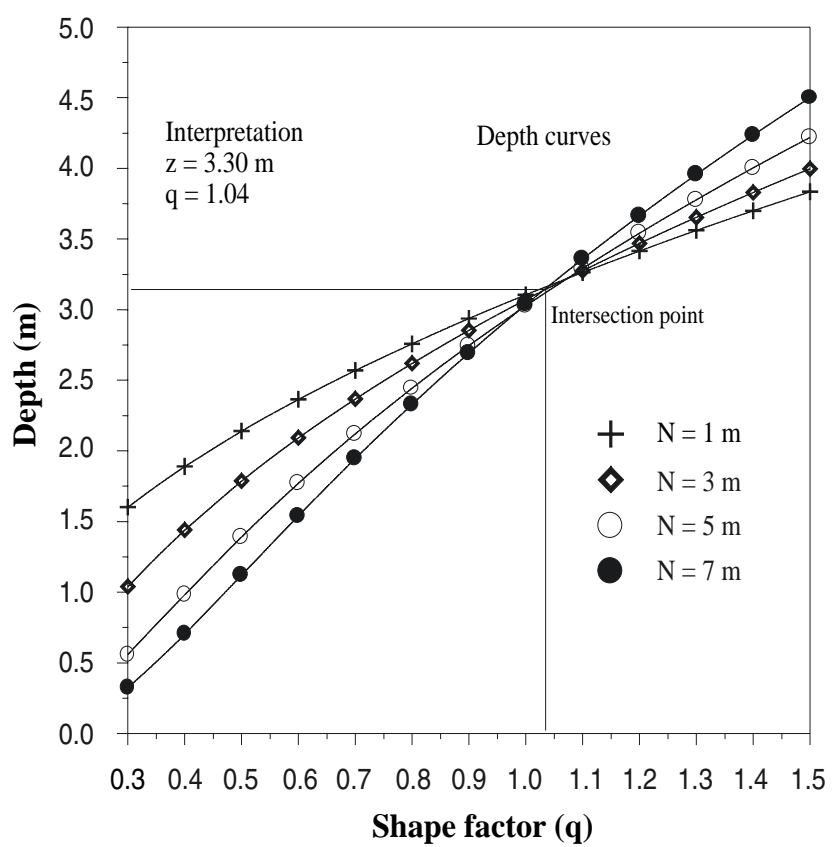

Fig. 9. Data interpretation of Figure 3 after adding $10 \%$ random errors using the present depth curves method.

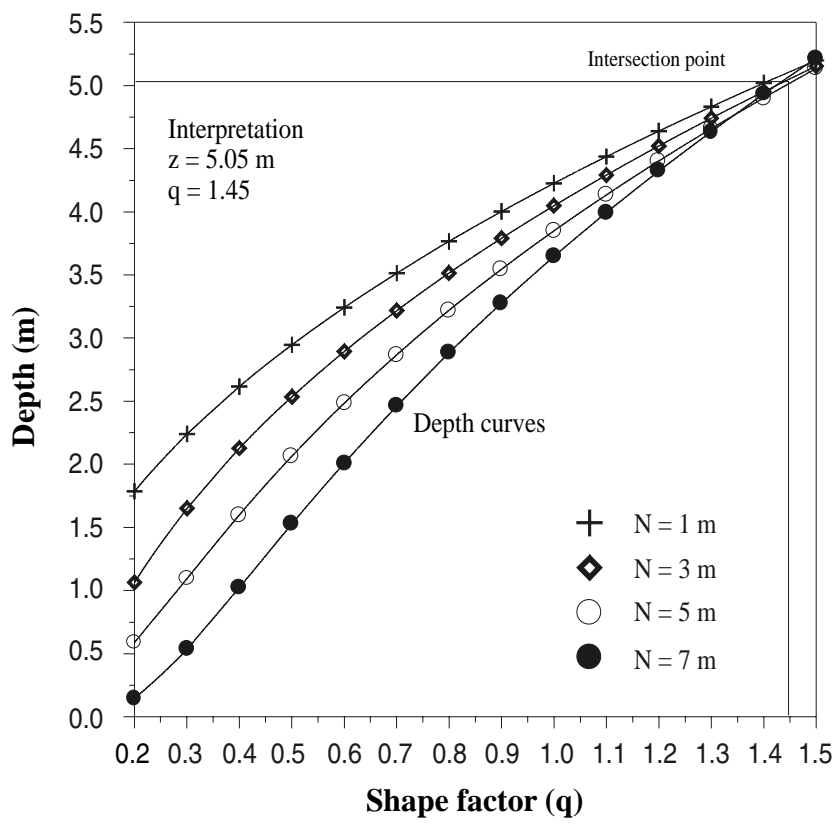

FIG. 10. Data interpretation of Figure 4 after adding 10\% random errors using the present depth curves method. 


\section{Field Example}

A self-potential anomaly profile along line 22 of the map of self-potential data over a Malachite Mine, Jefferson County, Colorado (Dobrin, 1960, Figure $19-25$, p. 426) is shown in Figure 11. The SP anomaly measurements were performed and described by Heiland et al. (1945). This anomaly profile was digitized at an interval of 6.6 meters. Equation (6) was applied using $\mathrm{N}=26.4$, 33.0, 39.6, 46.2, and $52.8 \mathrm{~m}$ to generate the depth curves. The results are given in Table 7 and shown in Figure 12. The depth curves intersect each other at $\mathrm{z}=$ $11.2 \mathrm{~m}$ and $\mathrm{q}=0.54$. This suggests the shape of ore body resembles a semiinfinite vertical cylinder buried at depth of $11.2 \mathrm{~m}$. The depth to the top of the ore body obtained by present method $(11.2 \mathrm{~m})$ agrees very well with that from drilling information (13.7 m) (Dobrin, 1960).

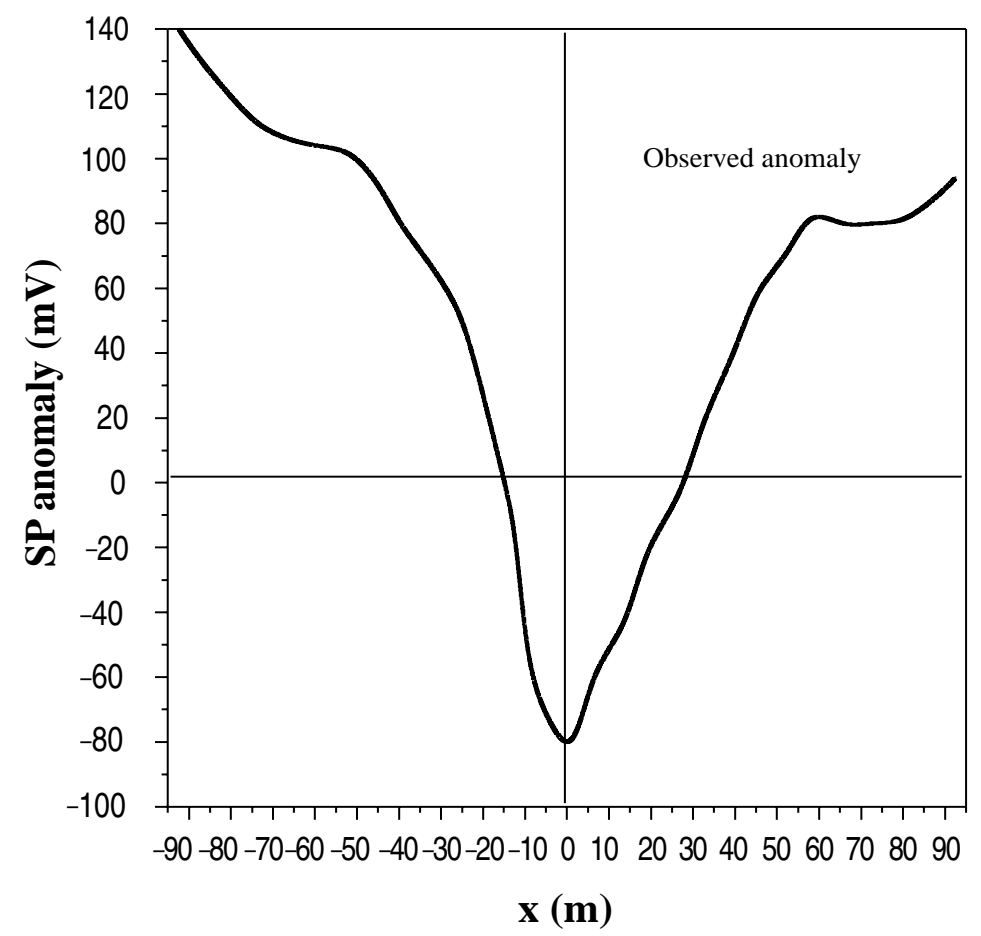

FIG. 11. Observed SP profile on line 22 of the map of self-potential data over a Malachite Mine, Jefferson County, Colorado (Dobrin, 1960). 


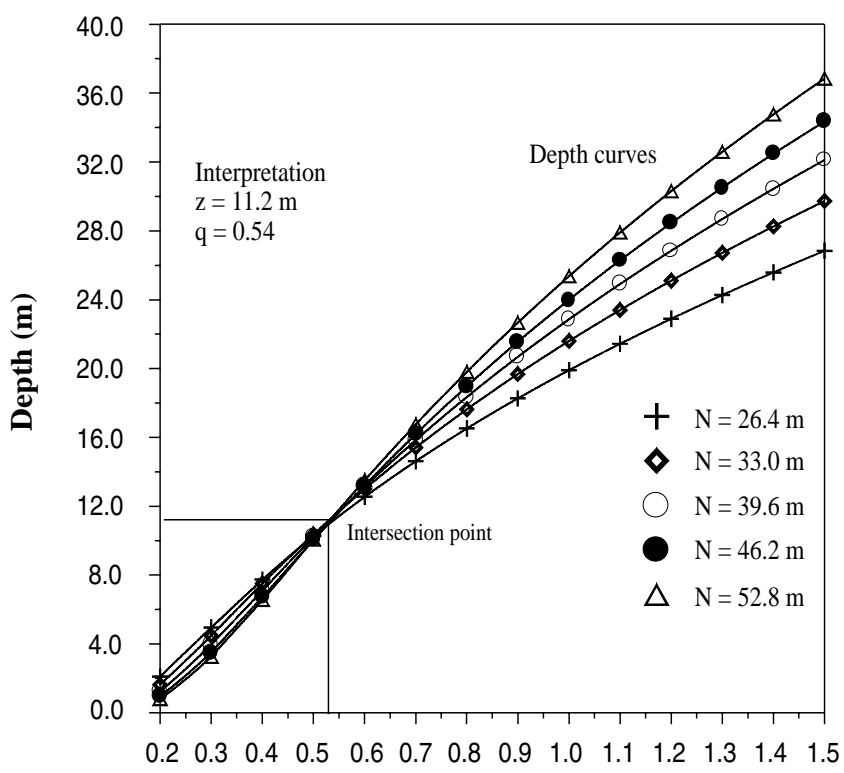

Shape factor (q)

FIG. 12. Data interpretation of Figure 11 using the present depth curves method.

TABLE 7. Numerical results of the field example

\begin{tabular}{|c|c|c|c|c|c|}
\hline \multirow{2}{*}{$\begin{array}{c}\text { Shape factor } \\
(\mathrm{q})\end{array}$} & \multicolumn{5}{|c|}{ Computed depths } \\
\cline { 2 - 6 } & $\mathrm{N}=26.4 \mathrm{~m}$ & $\mathrm{~N}=33.0 \mathrm{~m}$ & $\mathrm{~N}=39.6 \mathrm{~m}$ & $\mathrm{~N}=46.2 \mathrm{~m}$ & $\mathrm{~N}=52.8 \mathrm{~m}$ \\
\hline 0.2 & 2.095258 & 1.628716 & 1.238105 & 0.961908 & 0.803873 \\
\hline 0.3 & 4.950177 & 4.477238 & 3.948298 & 3.506070 & 3.249303 \\
\hline 0.4 & 7.738144 & 7.514370 & 7.112371 & 6.736098 & 6.564725 \\
\hline 0.5 & 10.26842 & 10.37802 & 10.22467 & 10.04696 & 10.07875 \\
\hline 0.6 & 12.54857 & 13.00570 & 13.14218 & 13.21888 & 13.50725 \\
\hline 0.7 & 14.61830 & 15.41264 & 15.84534 & 16.19373 & 16.75665 \\
\hline 0.8 & 16.51546 & 17.62918 & 18.35054 & 18.97034 & 19.80863 \\
\hline 0.9 & 18.27061 & 19.68457 & 20.68198 & 21.56531 & 22.67208 \\
\hline 1.0 & 19.90755 & 21.60357 & 22.86307 & 23.99917 & 25.36430 \\
\hline 1.1 & 21.44480 & 23.40632 & 24.91421 & 26.29154 & 27.90393 \\
\hline 1.2 & 22.89691 & 25.10907 & 26.85254 & 28.45975 & 30.30834 \\
\hline 1.3 & 24.27543 & 26.72501 & 28.69230 & 30.51870 & 32.59293 \\
\hline 1.4 & 25.58968 & 28.26492 & 30.44533 & 32.48100 & 34.77100 \\
\hline 1.5 & 26.84729 & 29.73766 & 32.12151 & 34.35732 & 36.85402 \\
\hline
\end{tabular}




\section{Conclusion}

The problem of determining the shape and depth of a buried structure from residual SP anomaly profile can be solved using the present method for simple anomalies. The depth curves method is very simple to execute and works well even when the SP data contain measurement errors and/or geologic noise within $(10 \%)$ magnitude of the SP anomaly. Theoretical and field examples illustrated the efficiency of the present method in determining the shape and depth of a buried structure from SP data.

\section{References}

Abdelrahman, E.M., El-Araby, T.M., Ammar, A.A. and Hassanein, H.I. (1997a) A leastsquares approach to shape determination from self-potential anomalies: Pure and Applied Geophysics, 150: 121-128.

Abdelrahman, E.M., Ammar, A.A., Sharafeldin, S.M. and Hassanein, H.I. (1997b) Shape and depth solutions from numerical horizontal self-potential gradients: Applied Geophysics, 36: 31-43.

Abdelrahman, E.M., Ammar, A.A., Hassanein, H.I. and Hafez, M.A. (1998) Derivative analysis of SP anomalies: Geophysics, 63: 890-897.

Abdelrahman, E.M., El Araby, T.M., El Araby, H.M., Ammar, A.A. and Hassanein, H.I. (1999) Shape and depth solutions from moving average residual self-potential anomalies: Kuwait Journal of Science \& Engineering, 26: 321-336.

Bhattacharya, B.B. and Roy, N. (1981) A note on the use of nomograms for self-potential anomalies: Geophys. Prospect., 29: 102-107.

Demidovich, B.P. and Maron, I.A. (1973) Computational mathematics, Mir. Publ.

Dobrin, M.B. (1960) Introduction to geophysical prospecting: McGraw-Hill Book Company, Inc.

Heiland, C.A., Tripp, R.M. and Wantland, D. (1945) Geophysical surveys at the Malachite Mine, Jefferson County, Colorado: Geophysics, Trans. Am. Inst. Mining Met. Engrs., 164: 142-154.

Stanley, J.M. (1977) Simplified magnetic interpretation of the geologic contact and thin dike: Geophysics, 42: 1236-1240. 
تعيـين الشـكل والعمـق من شـاذات الجهـــد التلقـائي باستخـــام طريقـة تكراريــة بسيطـة

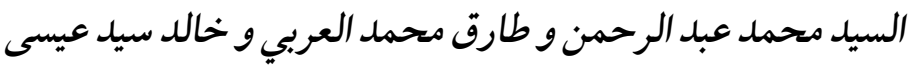
قسم الجيوفيزياء ، كلية العلوم، جامعة القاهرة ، الجيزة

المستخلص. نقدم في هذا البحث طريقة عددية بسيطة لتعيين الشكل

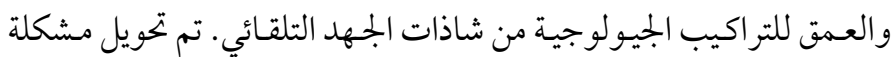

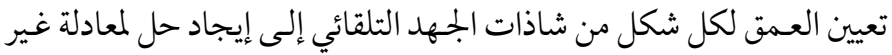

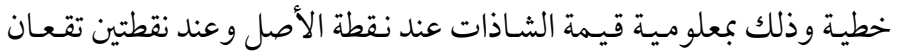

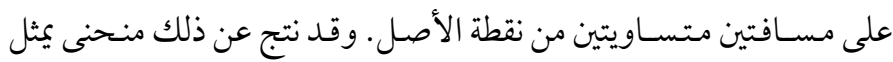

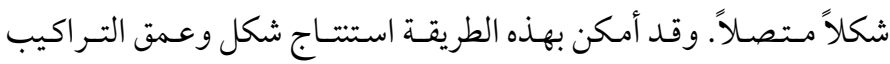

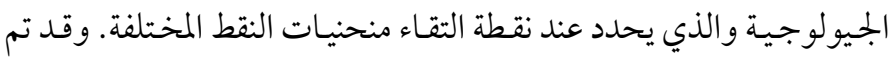

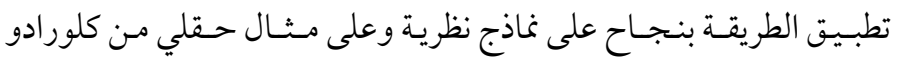

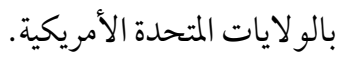

